ИЗВЕСТИЯ АКАДЕМИИ НАУК ЭСТОНСКОИ ССР. ТОМ 27 ФИЗИКА * МАТЕМАТИКА. 1978, № 3

\title{
ВЛИЯНИЕ ПОРИСТОГО ПОКРЫТИЯ ПОВЕРХНОСТИ НАГРЕВА НА ИНТЕНСИВНОСТЬ ТЕПЛООТДАЧИ ПРИ КИПЕНИИ ЖИДКИХ ДИЭЛЕКТРИКОВ
}

Определение коэффициентов теплоотдачи при кипении фторорганических жидких диэлектриков на поверхности с пористым покрытием, т. е. характера изменения теплового потока в зависимости от температуры поверхности, составляет основное содержание задачи исследования граничных условий. Коэффициенты теплоотдачи определялись нами экспериментально, так как кипение жидкого диэлектрика на поверхности, покрытой пористым материалом, слишком сложный процесс, чтобы составить математическую модель и получить точное решение только путем расчетов. Исследования проводились при изменении плотности тепловых потоков от величины $2 \cdot 10^{3} B T / \mu^{2}$, соответствующей началу кипения фторорганических диэлектриков, до критических значений, при которых пузырьковое кипение переходит в пленочное. Предварительно были определены основные параметры пористых покрытий (табл. 1).

В известных работах по изучению кипения жидкостей на поверхностях с пористым покрытием $\left[{ }^{2-6}\right]$ приводятся лишь такие характеристики материалов, как их пористость, средний и реже минимальный радиусы пор. Нами основное внимание уделено проницаемости пористого покрытия и распределению пор по размерам, поскольку поры при кипении играют роль не только активных центров парообразования, но и служат каналами для течения пара и жидкости.

Теплопроводность материалов определяли методом пластины в стационарном режиме [7]. Открытую пористость измеряли взвешиванием сухого и насыщенного бензолом образца пористого материала: Прибли-

Параметры пористых материалов

таблица 1

\begin{tabular}{|c|c|c|c|c|c|c|c|}
\hline \multirow{2}{*}{ Материал } & \multirow{2}{*}{$\begin{array}{l}\text { Пори- } \\
\text { стость } \\
\quad \varepsilon\end{array}$} & \multirow{2}{*}{$\begin{array}{c}\text { Прони- } \\
\text { цаемость } \\
\kappa, M^{2}\end{array}$} & \multicolumn{4}{|c|}{ Радиус пор, $M$} & \multirow{2}{*}{ 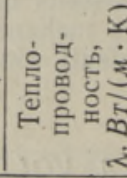 } \\
\hline & & & $a_{\text {Makc }}$ & $a_{\mathrm{Mma}}$ & $a_{\partial \phi}$ & $\bar{a}$ & \\
\hline \multirow{3}{*}{$\begin{array}{l}\text { Асбест } \\
\text { Х/б нитка } \\
\text { Стеклоткань } \\
\text { Пористая } \\
\text { медь } \\
\text { Карбид } \\
\text { кремния }\end{array}$} & $\begin{array}{l}0,90 \\
0,80 \\
0,90\end{array}$ & $\begin{array}{l}1,2 \cdot 10^{-5} \\
5 \cdot 10^{-7} \\
1 \cdot 10^{-8}\end{array}$ & $\begin{array}{l}\approx 10^{-4} \\
\approx 10^{-4} \\
\approx 10^{-4}\end{array}$ & $\begin{array}{l}1-2 \cdot 10^{-9}[1] \\
1 \cdot 10^{-6} \\
0,5 \cdot 10^{-6}\end{array}$ & Z & $\bar{z}$ & $\begin{array}{l}0,390 \\
0,170 \\
0,105\end{array}$ \\
\hline & 0,69 & $1,8 \cdot 10^{-12}$ & $6,2 \cdot 10^{-6}$ & $1,5 \cdot 10^{-6}$ & $1,75 \cdot 10^{-6}$ & $2,85 \cdot 10^{-6}$ & 13,800 \\
\hline & 0,30 & $2 \cdot 10^{-13}$ & $5,5 \cdot 10^{-6}$ & $0,5 \cdot 10^{-6}$ & $0,8 \cdot 10^{-6}$ & $2,5 \cdot 10^{-6}$ & 1,530 \\
\hline
\end{tabular}


Характеристики экспериментальных участков у

Таблица 2 неэлектропроводящих материалов

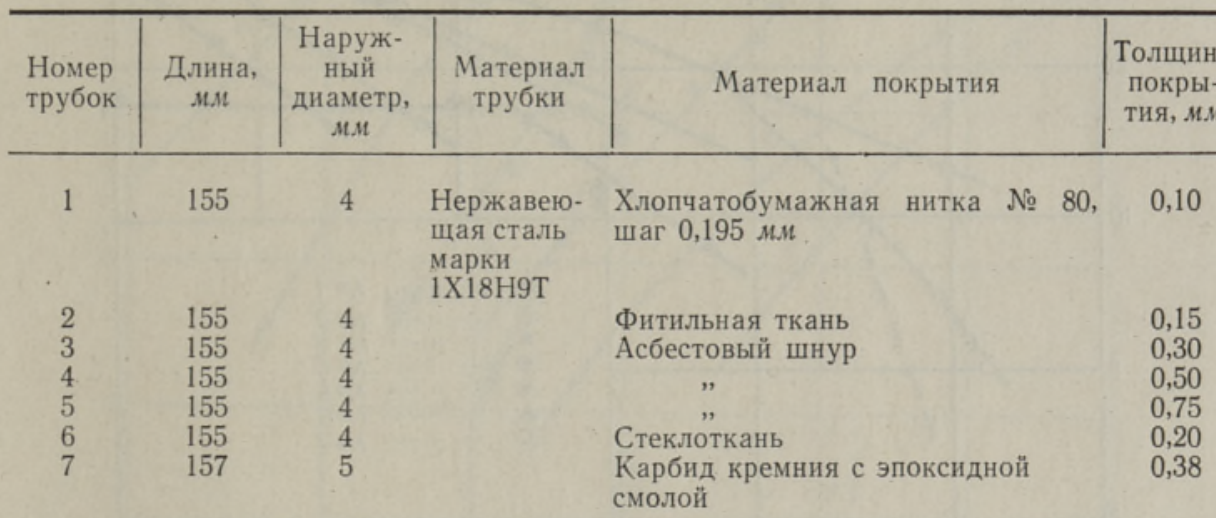

женное аналитическое выражение дифференциального распределения объемов пор по радиусам, определенного экспериментально, для спеченных покрытий $\left[{ }^{8}\right]$ рассчитывали по формуле

$$
\frac{d V}{d a}=\frac{a-a_{\mathrm{MUH}}}{s^{2}} \mathrm{e}^{-\frac{a-a_{\mathrm{M} \mathrm{ин}}}{s}},
$$

где $V$ - объем пор, $a$ - радиус пор, $s$ - дисперсия (см. рис. 1).

У волокнистых материалов (асбеста, хлопчатобумажной нитки, стеклоткани) распределение пор по размерам не исследовали ввиду отсутствия у них твердого скелета.

На первом этапе тепловых испытаний изучали тонкие волокнистые покрытия из неэлектропроводящих материалов. Экспериментальная установка и использованная методика описаны в $\left[{ }^{9}\right]$. Размеры рабочих участков семи трубок и тип пористого покрытия приведены в табл. 2. В качестве рабочей жидкости использовали трифтортрихлорэтан (Ф-113). Изучение зависимости плотности теплового потока от перегрева поверхности трубки под пористым слоем относительно кипящего Ф-113 показывает, что интенсивность теплоотдачи увеличивается в области низких тепловых нагрузок (рис. 2). В случае трубки без покрытия критическая тепловая нагрузка наступает при $1,5 \cdot 10^{5} B T / M^{2}$.

Рис. 1. Дифференциальное распределение объемов пор. Карбнд кремния с эпоксидной смолой $(1)$, пористая медь (2), $\gamma$-распределение при $s=0,2$ и $a_{\text {мин }}=0,5$ мкм (3) и $s=0,3, a_{\text {мнн }}=1,5$ мКм (4).

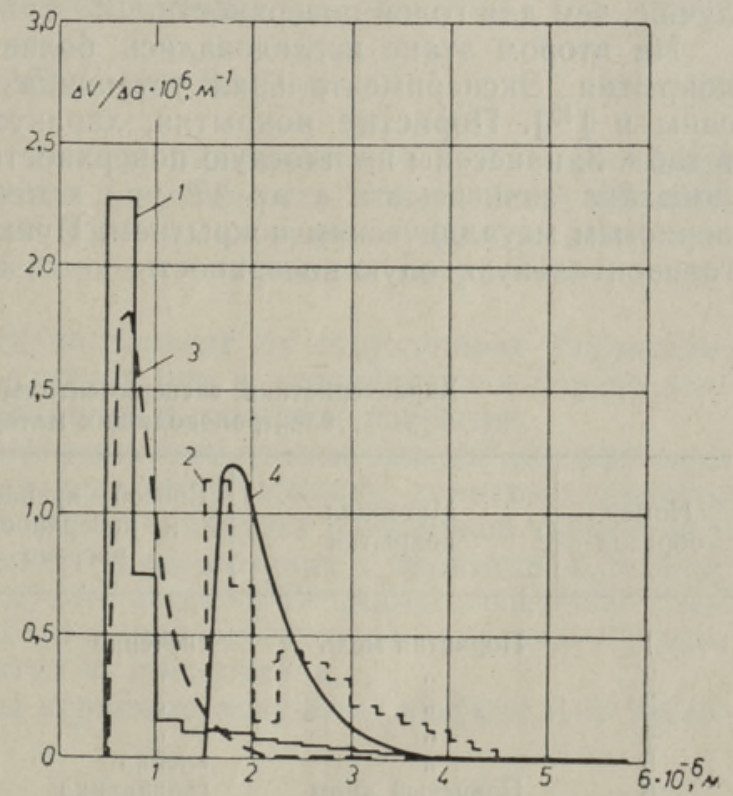




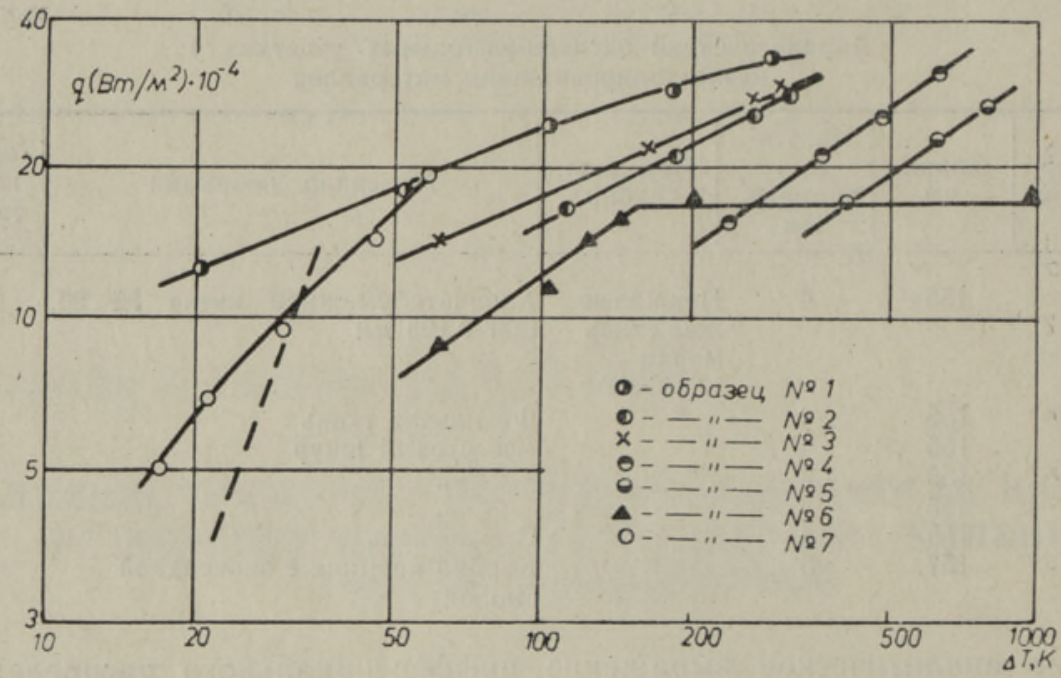

Рис. 2. Зависимость плотности теплового потока от перегрева поверхности горизонтальной трубки относительно температуры кипения $Ф-113$.

Отметим, что под кризисом кипения мы понимаем момент пленкообразования между пористым слоем и жидкостью, а под критической плотностью - плотность теплового потока, при которой наблюдается этот процесс. При асбестовом и хлопчатобумажном покрытиях кризис не наступал даже при $3 \cdot 10^{5} B T / \mu^{2}$ (предельной тепловой нагрузке для использованной экспериментальной установки), хотя температура поверхности нагрева превышала критическую для $\Phi$-113. Все кривые $q=$ $=f(\Delta T)$ на рис. 2 для изученных пористых покрытий ймеют меньший наклон в логарифмических координатах по сравнению с кривой для голой трубки (пунктирная линия). Для покрытий из $\mathrm{x} / б$ нитки и карбида кремния теплоотдача в области малых значений тепловых потоков лучше, чем для голой поверхности.

На втором этапе исследовались более толстые электропроводящие покрытия. Экспериментальная установка и методика испытаний описаны в $\left[{ }^{10}\right]$. Пористые покрытия, характеристики которых приведены в табл. 3, нанесены на плоскую поверхность диаметром 22 мм. На рис. 3 показана зависимость $q$ от $\Delta T$ при кипении $\Phi-113$ на поверхности с пористым металлическим покрытием. Пунктирная кривая иллюстрирует горизонтальную голую поверхность.

Характеристики экспериментальных участков у

таблица 3 электроповодящих материалов

\begin{tabular}{c|c|c|c|c}
\hline $\begin{array}{c}\text { Номер } \\
\text { образца }\end{array}$ & $\begin{array}{c}\text { Материал } \\
\text { покрытия }\end{array}$ & $\begin{array}{c}\text { Способ крепления } \\
\text { к поверхности } \\
\text { нагрева }\end{array}$ & $\begin{array}{c}\text { Толщина } \\
\text { покры- } \\
\text { тия, } \boldsymbol{M \mu}\end{array}$ & $\begin{array}{c}\text { Пори- } \\
\text { стость, } \\
\%\end{array}$ \\
\hline
\end{tabular}

Пористая медь

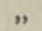

,

$"$

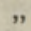

Пористый хром спечение

"

,

"

клейка

гальваника
1,00

2,15

4,10

6,20

0,90

0,20 


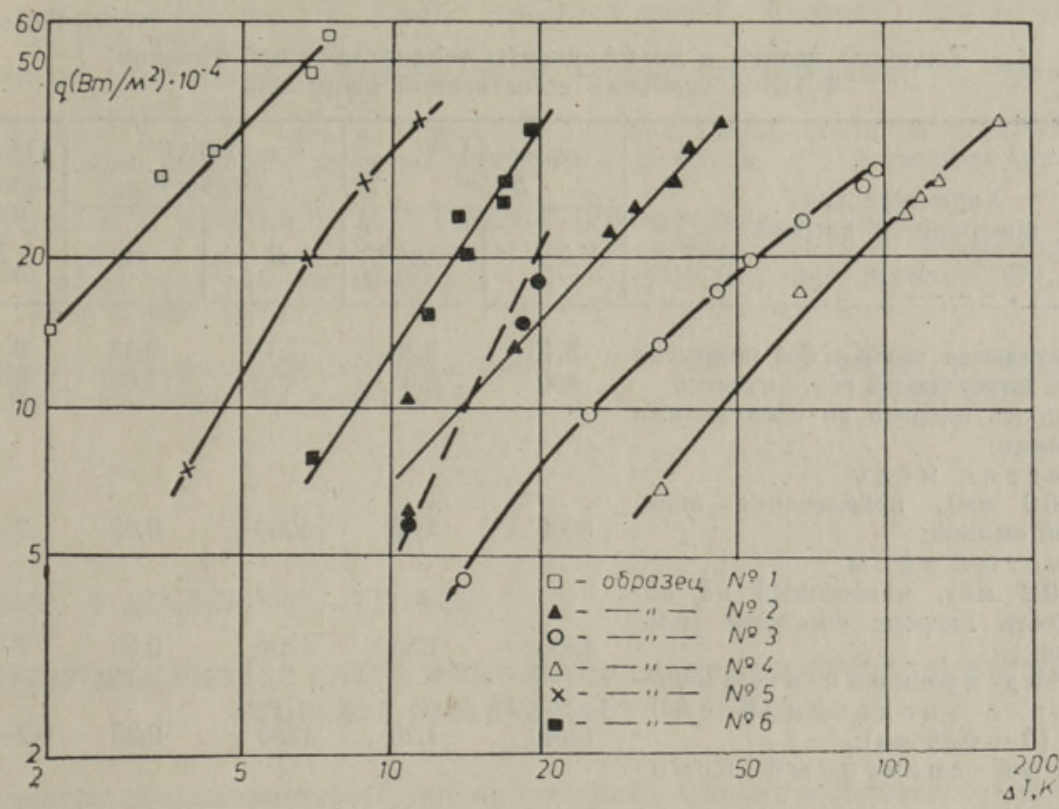

Рис. 3. Зависимость плотности теплового потока от перегрева горизонтальной плоской поверхности относительно температуры кипения Ф-113.

Существенное увеличение критической тепловой нагрузки и коэффициента теплоотдачи дает медное пористое покрытие толщиной 1 мм. Наклон кривых меньше, чем для голой поверхности, но существенно больше, чем в случае волокнистых покрытий. Улучшение теплоотдачи имеет место также при покрытии из пористого электролитического хрома и при наличии на поверхности нагрева медного пористого покрытия с подслоем из эпоксидной смолы.

Влияние пористых покрытий поверхности нагрева на граничные условия можно представить зависимостями

$$
q=A \Delta T^{n}, \quad \alpha=B \Delta T^{m} .
$$

Исследование коэффициентов пропорциональности $A$ и $B$, показателей степени $n$ и $m$, а также пределов применимости зависимостей (2) (см. табл. 4) позволяют сделать относительно кипения фторорганических жидких диэлектриков на поверхности с пористым покрытием следующие выводы.

1. Коэффициенты теплоотдачи зависят от структурных характеристик покрытия: пористости, размеров пор и распределения пор по размерам, а также от теплопроводности и толщины покрытия.

2. С повышением плотности теплового потока или $\Delta T$ коэффициенты теплоотдачи а) возрастают при использовании пористого медного покрытия, приклеенного к поверхности нагрева эпоксидной смолой; пористого хрома и карбида кремния в композиции с эпоксидной смолой; б) остаются постоянными в случае применения медного спеченного порошка и в) убывают при использовании асбестового и хлопчатобумажного покрытий, а также покрытия из стеклоткани.

3. С увеличением толщины пористого покрытия коэффициент теплоотдачи уменьшается. 


\section{Тепловые потоки и коэффициенты теплоотдачи при кипении} Ф-113 в условиях естественной конвекции

\begin{tabular}{|c|c|c|c|c|c|}
\hline \multirow{2}{*}{$\begin{array}{c}\text { Характеристика } \\
\text { поверхности нагрева }\end{array}$} & \multicolumn{2}{|c|}{$q=\underset{B T / M^{2}}{A}$} & \multicolumn{2}{|c|}{$\begin{array}{c}\alpha=B \Delta T^{m} \\
B T / M^{2} \cdot \mathrm{K}\end{array}$} & \multirow{2}{*}{$\begin{array}{c}\text { Пределы } \\
\text { примени- } \\
\text { мости } \\
\text { по } \\
\Delta T, \mathrm{~K}\end{array}$} \\
\hline & A & $n$ & $B$ & $m$ & \\
\hline \multirow{8}{*}{ 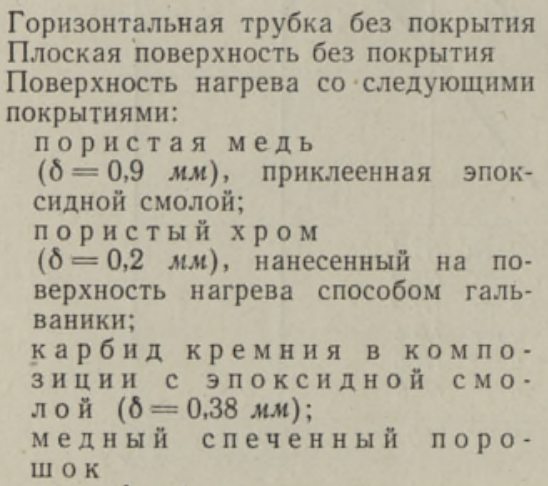 } & 3,45 & 3,33 & 3,45 & 2,33 & $8-28$ \\
\hline & 400 & 2,05 & 400 & 1,05 & $8-28$ \\
\hline & & & & & \\
\hline & & & & & \\
\hline & 8000 & 1,65 & 8000 & 0,65 & $3-11,5$ \\
\hline & & & & & \\
\hline & 4200 & 1,50 & 4200 & 0,50 & $7-20$ \\
\hline & 1380 & 1,25 & 1380 & 0,25 & $6,3-59$ \\
\hline $\begin{array}{l}\delta=1 \text { мм } \\
\delta=2,15 \text { мм } \\
\delta=4,1 \text { мм } \\
\delta=6,2 \text { м.; } \\
\text { с т к л о т к н ь }(\delta=0,2 \text { мм })\end{array}$ & $\begin{array}{r}73000 \\
7500 \\
3800 \\
2300 \\
5000\end{array}$ & $\begin{array}{l}1,00 \\
1,00 \\
1,00 \\
1,00 \\
0,7\end{array}$ & $\begin{array}{r}73000 \\
7500 \\
3800 \\
2300 \\
5000\end{array}$ & $\begin{array}{l}0 \\
0 \\
0 \\
0 \\
-0,3\end{array}$ & $\begin{array}{l}2-7,8 \\
10-48 \\
14-90 \\
36-170 \\
50-140\end{array}$ \\
\hline $\begin{array}{c}\text { а с бе с товы й шн у р } \\
\delta=0,5 \\
\delta=0,75 \\
\delta=0,3\end{array}$ & $\begin{array}{r}3350 \\
2500 \\
28500\end{array}$ & $\begin{array}{l}0,7 \\
0,7 \\
0,4\end{array}$ & $\begin{array}{r}3350 \\
2500 \\
28500\end{array}$ & $\begin{array}{l}-0,3 \\
-0,3 \\
-0,6\end{array}$ & $\begin{array}{r}200-630 \\
400-800 \\
60-320\end{array}$ \\
\hline $\begin{array}{l}\text { хлоп ч а тобум ажная ни тка } \\
(\delta=0,3 \text { мм }) ; \\
\phi \text { и ти льн ая ткань }\end{array}$ & 38000 & 0,4 & 38000 & $-0,6$ & $20-200$ \\
\hline $\begin{array}{l}\phi \text { и ти ль н а я тк ан ь } \\
(\delta=0,15 \mu M)\end{array}$ & 26000 & 0,4 & 26000 & $-0,6$ & $100-320$ \\
\hline
\end{tabular}

4. В случае тонкого слоя пористой меди на поверхности коэффициент теплоотдачи увеличивается по сравнению с таковым для голой поверхности до 10 раз.

5. Критическая плотность теплового потока на поверхности с покрытием увеличивается по сравнению с соответствующим показателем для голой поверхности в $1,4-2,5$ раза.

\section{Л ИТЕРА Т У Р А}

1. Pundsack, F. L. Pore structure of chrysotile asbestos. - J. Phys. Chem., 1961, v. $65, \mathrm{~N} 1$, p. $30-35$.

2. Колач Т. А., Шари пов Р. Х., Ягов В. В. Исследование теплообмена при кипении воды, подводимой к поверхности нагрева капиллярно-пористым телом при пониженных давлениях. - ИФЖ, 1968, т. 11, № 6, с. 975-982.

3. A $11 \mathrm{ingham}$, W. D., McEntire, J. A. Determination of boiling film coefficient for a heated horizontal tube in water-saturated wick material. - Trans. ASME, 1961, Ser. C 83 , N 1, p. $71-76$.

4. New heat-exchanger tubes make their commercial debut. - Chemical Engng., 1970, v. $77, \mathrm{~N} 5, \mathrm{p}, 60-62$.

5. Costello, C. P., Frea, W. J. The roles of capillary wicking and surface deposits in the attainment of high pool boiling burnout. - AIChE Journal, 1964, v. 10, N 3, p. 393-398.

6. Ferreil, J. W., Alle avitch, J. Final report on a stydy of the operating characteristics of the heat pipe at North Carolina State Univ. Raleigh. Research 
conducted for the US Atomic Energy Commiss. .Contract AT-(40-1)3411. P. 1-3. Raleigh, 1969 .

7. Методы спредсления теплопроводности и температуропроводности. (Под. ред. А. В. Лыкова). М., 1973.

8. В икторов С. И. Теория и практика способа экспериментальной оценки проницаемости тонких пористых диафрагм и фильтров. - Порошковая металлургия, 1971, № 9, с. $72-79$.

9. Т уник А. Т. Охлаждение РЭА жидкими диэлектриками. М., 1973.

10. Т ехвер Я., Т уник А. О кризисе теплоотдачи при кипении на поверхности, покрытой пористым материалом. - Изв. АН ЭССР, Физ. Матем., 1977, т. 26, № 2, c. $194-198$.

Институт термофизики и электрофизики Академии наук Эстонской ССР

Поступила в редакцию 17/III 1977

A. TUNIK, A. BOLSAKOV, J. TEHVER

\title{
KUTTEPINNA POORSE KATTE MOJU SOOJUSULEKANDE INTENSIIVSUSELE VEDELATE DIELEKTRIKUTE KEEMISEL
}

On kirjeldatud soojusülekandekoefitsientide määramist trifluortriklooretaani keemisel mitmesuguste poorsete materjalidega kaetud pinnal ning iseloomustatud kasutatud katteid (materjal, poorsus, läbitavus, pooride jaotus suuruse järgi, kihi paksus, soojusjuhtivus). Soojusülekande muutumist sõltuvalt kattest väljendavad valemid $q=A \Delta T^{n}$ ja $\alpha=B \Delta T^{m}$.

\author{
A. TUNIK, A. BOLSHAKOV, J. TEHVER
}

\section{ON THE INFLUENCE OF POROUS COATING OF THE HEATING SURFACE TO THE RATE OF HEAT TRANSFER AT BOILING LIQUID DIELECTRICS}

In this experimental study the authors have investigated the rate of heat transfer to boiling trifluortrichlorethane (F-113) from surfaces coated with various porous materials. The main characteristics (material, porosity, permeability, distribution of pores, thickness, coefficient of heat passage) are given. The influence of porous coating on the boundary conditions is presented by $q=A \Delta T^{n}$ and $\alpha=B \Delta T^{m}$. 